\title{
N-METIL LAUROTETANIN DAN BOLDIN, DUA SENYAWA TURUNAN ALKALOID APORFIN DARI Cryptocarya tawaensis Merr (Lauraceae)
}

Fera Kurniadewi ${ }^{a}$, Yana M. Syah ${ }^{b}$, Lia D. Juliawaty ${ }^{b}$ dan Euis H. Hakim ${ }^{b}$

a Jurusan Kimia, Fakultas Matematika dan Ilmu Pengetahuan Alam, Universitas Negeri Jakarta, Rawamangun 13220, Jakarta

${ }^{\mathrm{b}}$ Kelompok Penelitian Kimia Organik Bahan Alam, Departemen Kimia, Institut Teknologi Bandung, Jalan Ganeca 10 Bandung 40132, Indonesia

*Corresponding author: ehhakim@yahoo.com

\begin{abstract}
Abstrak
Cryptocarya (Lauraceae), yang dikenal dengan nama daerah "medang" merupakan salah satu kelompok tumbuhan endemik hutan tropik Indonesia. Kelompok tumbuhan ini secara fitokimia merupakan penghasil metabolit sekunder golongan alkaloid, $\alpha$-piron, flavonoid dan triterpen. Berkaitan dengan hal tersebut di atas, kajian fitokimia terhadap senyawa alkaloid dari spesies Cryptocarya tawaensis Merr (Lauraceae) belum pernah dilaporkan sebelumnya. Hasil penelitian terhadap spesies ini telah berhasil diisolasi dan diidentifikasi dua senyawa turunan alkaloid aporfin, yaitu $N$-metillaurotetanin (1) dan boldin (2), dimana struktur molekul kedua senyawa tersebut ditetapkan berdasarkan sifat fisika, data spektroskopi UV, IR, ${ }^{1} \mathrm{H}-\mathrm{NMR}$ dan serta perbandingan dengan data senyawa standar yang telah dilaporkan. Senyawa 1 pernah dilaporkan sebelumnya dari spesies $C$. longifolia, sementara senyawa $\mathbf{2}$ baru pertama kali ditemukan dalam tumbuhan Cryptocarya. Berdasarkan penemuan kedua senyawa tersebut, dapat disimpulkan bahwa $C$. tawaensis dapat dikelompokkan ke dalam tumbuhan Cryptocarya penghasil alkaloid.
\end{abstract}

Kata kunci: Alkaloid, Aporfin, N-metil laurotetanin, boldin, Cryptocarya tawaensis Merr, Lauraceae

\section{Pendahuluan}

Tumbuhan Cryptocarya yang di Indonesia lebih dikenal dengan nama daerah "medang" atau "huru" termasuk dalam tumbuhan famili Lauraceae. Genus Cryptocarya memiliki sekitar 200 spesies yang tersebar di daerah Asia, Australia dan Melanesia. ${ }^{1}$ Hasil penelusuran literatur memperlihatkan bahwa kajian fitokimia telah dilakukan terhadap 37 dari 200 spesies Cryptocarya, 13 spesies diantaranya berasal dari Indonesia. ${ }^{2}$ Dari hasil penelitian tersebut diketahui bahwa Cryptocarya menghasilkan beberapa jenis metabolit sekunder antara lain yang termasuk golongan senyawa alkaloid, $\alpha$-piron, flavonoid, lignan, terpenoid, dan steroid dimana kandungan kimia yang paling banyak ditemukan dari genus ini adalah senyawa turunan alkaloid dan $\alpha$-piron. ${ }^{3}$ Salah satu spesies Cryptocarya yaitu tawaensis Merr., dipilih sebagai sampel penelitian ini, karena kajian fitokimianya belum pernah dilaporkan sebelumnya. Dalam makalah ini akan disampaikan penemuan senyawa turunan alkaloid aporfin, yaitu $N$ - metillaurotetanin (1) dan boldin (2) dari ekstrak metanol kulit batang $C$. tawaensis Merr. Struktur molekul senyawa-senyawa tersebut ditetapkan berdasarkan data spektroskopi UV, IR, NMR 1-D, dan NMR 2-D serta perbandingan dengan data sejenis yang telah dilaporkan. Sedangkan sifat sitotoksiknya ditentukan dengan menggunakan sel murin leukemia P388.

\section{Metodologi Penelitian}

Umum. Titik leleh ditentukan dengan 'micro melting point apparatus'. Putaran optik diukur dengan polarimeter Perkin-Elmer 341 dalam $\mathrm{MeOH}$. Spektrum UV dan IR ditetapkan dengan Cary Varian 100 Conc. dan Perkin-Elmer Spectrum One FT-IR spectrophotometers. Spektrum ${ }^{1} \mathrm{H}$ ditentukan dengan spektrofotometer JEOL ECP400, yang beroperasi pada $400 \mathrm{MHz}\left({ }^{1} \mathrm{H}\right)$. Kromatografi cair vakum menggunakan Si-gel $60 \quad \mathrm{GF}_{254}$ (Merck), kromatografi kolom tekan menggunakan Si-gel 60 (230-400 mesh) (Merck), kromatografi radial menggunakan Sigel $60 \mathrm{PF}_{254}$ (Merck), dan analisis KLT menggunakan plat KLT Kieselgel $60 \mathrm{GF}_{254}$ 0,25 
$\mathrm{mm}$ (Merck). Pelarut yang digunakan semuanya berkualitas teknis yang didestilasi.

Bahan. Sampel tumbuhan berupa kulit batang C. tawaensis Merr. dikumpulkan dari daerah Taman Nasional Kalimantan Barat. Tumbuhan tersebut diidentifikasi oleh staf Herbarium Bogorensis, Lembaga IImu Pengetahuan Indonesia (LIPI) Bogor.

Ekstraksi dan Isolasi. Serbuk kulit batang $C$. tawaensis Merr. seberat $1.5 \mathrm{Kg}$ dimaserasi dengan $\mathrm{MeOH}$ kemudian diuapkan menggunakan rotary evaporator pada tekanan rendah menghasilkan ekstrak $\mathrm{MeOH}$ kering seberat 111 gram. Ekstrak $\mathrm{MeOH}$ tersebut dilarutkan dalam campuran $\mathrm{MeOH}$ dan air (1:1) kemudian ditambahkan asam tartarat $1 \%$ sehingga terbentuk endapan. Setelah dilakukan penyaringan untuk memisahkan endapan yang terbentuk, dilakukan partisi cair-cair terhadap fasa $\mathrm{MeOH}$-air dengan menambahkan EtOAc $(3 \times 200 \mathrm{~mL})$. Fraksi yang terlarut dalam EtOAc kemudian diuapkan sehingga mendapatkan ekstrak EtOAc kering yang mengandung senyawa non alkaloid seberat 11 gram. Fraksi yang terlarut dalam $\mathrm{MeOH}$-air dibasakan dengan menambahkan $\mathrm{NH}_{3}$ sampai $\mathrm{pH}$ mencapai 8-9. Fasa $\mathrm{MeOH}$-air tersebut dipartisi cair-cair dengan menambahkan EtOAc (3x200mL) menghasilkan ekstrak EtOAc yang mengandung senyawa alkaloid seberat 3.086 gram. Terhadap ekstrak EtOAc tersebut dilakukan fraksinasi menggunakan kromatografi vakum cair dengan eluen campuran heksan:EtOAc yang ditingkatkan kepolarannya menghasilkan 7 fraksi: $A(5 \mathrm{mg}), B(3 \mathrm{mg}), C(211$ $\mathrm{mg}), \mathrm{D}$ (306 mg), $E(260 \mathrm{mg}), F(652 \mathrm{mg})$ dan $\mathrm{G}(151 \mathrm{mg})$. Fraksi $C$ dan D digabung, terhadap fraksi tersebut dilakukan fraksinasi dengan kromatografi radial menggunakan eluen campuran $\quad \mathrm{CHCl}_{3} / \mathrm{H} / \mathrm{MeOH} \quad(6: 3.5: 0.5)$ menghasilkan 4 fraksi: $\mathrm{CD}_{1}(72 \mathrm{mg}), \mathrm{CD}_{2}(53 \mathrm{mg})$, $\mathrm{CD}_{3}(23 \mathrm{mg})$, dan $\mathrm{CD}_{4}(276 \mathrm{mg})$. Fraksi $\mathrm{CD}_{1}$ difraksinasi menggunakan kromatografi radial dengan eluen campuran $\mathrm{CHCl}_{3} / \mathrm{H} / \mathrm{MeOH}$ (6:3.8:0.2) menghasilkan senyawa 1 (20 mg). Fraksi E difraksinasi dengan kromatografi radial menggunakan eluen $\mathrm{H} / \mathrm{CHCl}_{3}$ menghasilkan 4 fraksi: $E_{1}(1 \mathrm{mg}), E_{2}(14 \mathrm{mg})$, $E_{3}(14 \mathrm{mg})$ dan $E_{4}(180 \mathrm{mg})$. Selanjutnya, dengan metoda pemisahan yang sama, fraksi $\mathrm{CD}_{4}$ difraksinasi menggunakan eluen campuran
$\mathrm{CHCl}_{3} / \mathrm{H} / \mathrm{MeOH}$ (6:3:1) menghasilkan 5 fraksi: $\mathrm{CD}_{41}(2 \mathrm{mg}), \mathrm{CD}_{42}(97 \mathrm{mg}), \mathrm{CD}_{43}(13 \mathrm{mg}), \mathrm{CD}_{44}(4$ $\mathrm{mg})$ dan $\mathrm{CD}_{45}(180 \mathrm{mg})$. Gabungan fraksi $\mathrm{E}_{4}$ dan $\mathrm{CD}_{45}$ dimurnikan dengan menggunakan kromatografi radial dengan eluen $\mathrm{CHCl}_{3} / \mathrm{MeOH}$ (9.5:0.5) menghasilkan senyawa 2.

Uji sifat biologis. Aktivitas biologis kedua senyawa tersebut dilakukan terhadap sel murin leukemia P-388 (sitotoksisitas).

\section{Hasil dan Pembahasan}

Senyawa 1 diperoleh sebagai gum berwarna coklat dan mempunyai putaran optik $[\alpha]_{D}{ }^{20}=+100.0$ (c $0,1 \mathrm{MeOH}$ ). Spektrum UV senyawa 1 dalam $\mathrm{MeOH}$ menunjukkan serapan pada $\lambda_{\text {maks }} 218,281$ dan $302 \mathrm{~nm}$. Spektrum UV ini memperlihatkan adanya kromofor alkaloid aporfin. Penambahan pereaksi geser $\mathrm{NaOH}$ mengindikasikan bahwa senyawa 1 memiliki hidroksil bebas yang ditunjukkan dengan adanya pergeseran batokromik sebesar $26 \mathrm{~nm}$. Dugaan senyawa alkaloid aporfin diperkuat spektrum IR yang memperlihatkan adanya vibrasi ulur C-O aril eter dan C-N pada $v_{\text {maks }} 1084$ dan $1238 \mathrm{~cm}^{-1}$ sedangkan serapan dari vibrasi ulur C-H alifatik muncul pada $v_{\text {maks }} 2933 \mathrm{~cm}^{-1}$ dan vibrasi ulur $\mathrm{C}=\mathrm{C}$ aromatik terlihat pada $\mathrm{v}_{\text {maks }}$ $1587-1464 \mathrm{~cm}^{-1}$, selain itu adanya vibrasi ulur $\mathrm{O}-\mathrm{H}$ terlihat pada $\mathrm{v}_{\text {maks }} 3420 \mathrm{~cm}^{-1}$. Spektrum ${ }^{1} \mathrm{H}$ NMR senyawa 1 memperlihatkan 3 sinyal proton aromatik singlet pada $\delta_{H} 6,56,6,77$, dan $8,02 \mathrm{ppm}$ yang sesuai dengan karakteristik sinyal proton aromatik singlet pada C-3, C-8, dan C-11. Adanya ketiga sinyal proton aromatik singlet tersebut menunjukkan cincin aromatik dari alkaloid aporfin tersebut tersubstitusi pada C-1, C-2, C-9, dan C-10 sebagaimana lazimnya aporfin pada tumbuhan Berdasarkan data spektroskopi tersebut maka struktur senyawa $\mathbf{1}$ disarankan $\mathrm{N}$-metillaurotetanin (9-hidroksi 1,2,10-trimetoksiaporfin) (1).

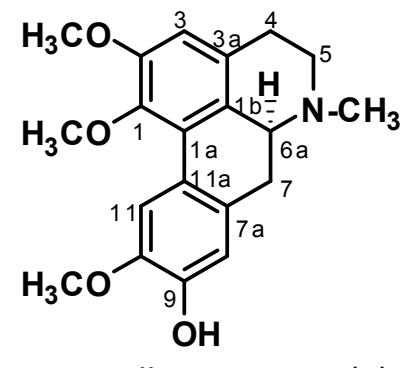

$N$-metillaurotetanin (1) 
Nilai pergeseran kimia dari spektrum ${ }^{1} \mathrm{H}-\mathrm{NMR},{ }^{13} \mathrm{C}-\mathrm{NMR}$ dan korelasi HMBC senyawa $\mathbf{1}$ dapat dilihat pada Tabel 1 berikut:

Tabel 1 Data spektrum ${ }^{1} \mathrm{H},{ }^{13} \mathrm{C}-\mathrm{NMR}$ dan HMBC N-Metillaurotetanin (1)

\begin{tabular}{|c|c|c|c|}
\hline No & $\delta_{\mathrm{H}}$ (mult. $J$ in $\mathrm{Hz}$ ) & $\delta_{\mathrm{C}} \mathbf{p p m}$ & HMBC $\left({ }^{1} H \Leftrightarrow^{13} \mathrm{C}\right)$ \\
\hline 1 & - & 151,8 & - \\
\hline $1 \mathrm{a}$ & - & 126,3 & - \\
\hline $1 b$ & - & 126,9 & - \\
\hline 2 & - & 144,0 & - \\
\hline 3 & $6,56(s)$ & 110,1 & C-1, C-1a, C-2, C-4 \\
\hline $3 a$ & - & 128,7 & - \\
\hline 4 & $\begin{array}{l}2,64(d d, 3,3 \& 16,1) \\
3,13(d d, 4,8 \& 16,1)\end{array}$ & 28,9 & C-3, C-3a, C-5 \\
\hline 5 & $\begin{array}{l}2,48(d d, 4,8 \& 12,1) \\
3,03(d d, 3,3 \& 12,1)\end{array}$ & 53,2 & $C-4, C-6 a$ \\
\hline $6 \mathrm{a}$ & $3,01(d d, 5,1 \& 13,5)$ & 62,4 & - \\
\hline 7 & $\begin{array}{l}2,54(d d, 9,5 \& 13,5) \\
2,93(d d, 5,1 \& 9,5)\end{array}$ & 34,0 & C-1a, C-6a, C-8 \\
\hline $7 \mathrm{a}$ & - & 123,7 & - \\
\hline 8 & $6,77(s)$ & 113,9 & C-7, C-7a, C-9 \\
\hline 9 & - & 145,3 & - \\
\hline 10 & - & 144,9 & - \\
\hline 11 & $8,02(s)$ & 112,1 & C-9, C-10, C-11a \\
\hline $11 \mathrm{a}$ & - & 129,8 & - \\
\hline $\mathrm{N}-\mathrm{CH}_{3}$ & $2,51(s)$ & 43,8 & - \\
\hline $1-\mathrm{OCH}_{3}$ & $3,65(s)$ & 60,0 & $\mathrm{C}-1$ \\
\hline $2-\mathrm{OCH}_{3}$ & $3,85(s)$ & 55,9 & $\mathrm{C}-2$ \\
\hline $10-\mathrm{OCH}_{3}$ & $3,65(s)$ & 55,7 & C-10 \\
\hline
\end{tabular}

Pembuktian lebih lanjut berkenaan dengan struktur senyawa 1 dilakukan dengan analisis spektrum HMBC dan NOESY. Spektrum HMBC senyawa 1 memperlihatkan adanya korelasi jarak jauh antara sinyal proton pada $\delta 6.77 \mathrm{ppm}$ $(\mathrm{H}-8)$ dengan sinyal-sinyal karbon pada $\delta 145,3$ (C-9) dan 123,7 (C-7a) ppm. Hal ini membuktikan bahwa gugus hidroksi terikat pada posisi C-9. Posisi gugus metoksi pada C-10 dapat dibuktikan dengan adanya korelasi jarak jauh antara sinyal proton pada $\delta_{\mathrm{H}} 8,02 \mathrm{ppm}(\mathrm{H}-$ 11) dengan sinyal karbon pada $\delta_{c} 129,8$ (C-11a) dan 144,9 (C-10) dan diperkuat spektrum NOESY yang memperlihatkan adanya korelasi antara proton pada $\delta_{\mathrm{H}} 8,02 \mathrm{ppm}(\mathrm{H}-11)$ dengan sinyal proton dari gugus metoksi pada $\delta_{\mathrm{H}} 3,65$ ppm $\left(10-\mathrm{OCH}_{3}\right)$. Dua gugus metoksi lainnya ditentukan berdasarkan adanya korelasi jarak jauh antara sinyal proton pada $\delta_{H} 6,56 \mathrm{ppm}$ $(\mathrm{H}-3)$ dengan sinyal-sinyal karbon pada $\delta_{\mathrm{C}} 144$ (C-2) dan 151,8 (C-1) ppm.
Sementara itu, dengan cara yang sama, struktur senyawa 2 ditentukan. Hasil perbandingan data UV, IR, NMR dari senyawa $\mathbf{2}$ dan senyawa $\mathrm{N}$-metillaurotetanin (1) memiliki tingkat kemiripan yang tinggi. (Tabel 2). Hal yang membedakan terlihat dari hilangnya sinyal dari satu gugus metoksil, dengan demikian maka substituen metoksil diganti dengan gugus hidroksil. Berdasarkan data spektroskopi tersebut dapat disimpulkan bahwa senyawa 2 adalah boldin (2,9-dihidroksi 1,10dimetoksiaporfin) (2).<smiles>COc1cc2c(cc1O)C[C@@H]1c3c(cc(O)c(O)c3-2)CCN1C</smiles> 
Tabel 2 Data spektrum ${ }^{1} \mathrm{H}$, dan ${ }^{13} \mathrm{C}-\mathrm{NMR}$ boldin (2)

\begin{tabular}{|c|l|c|c|}
\hline \multirow{2}{*}{ No. C } & \multicolumn{1}{|c|}{$\boldsymbol{\delta}_{\mathbf{H}}$ (multiplisitas, $\boldsymbol{J}$ dlm Hz) } & \multicolumn{2}{|c|}{$\boldsymbol{\delta}_{\mathbf{C}}$} \\
\cline { 2 - 4 } & \multicolumn{1}{|c|}{$\mathbf{2}$} & $\mathbf{2}$ & $\mathbf{2}^{*}$ \\
\hline 1 & - & 143,6 & 142,1 \\
$1 \mathrm{a}$ & - & 127,3 & 125,9 \\
$1 \mathrm{~b}$ & - & 127,2 & 125,9 \\
2 & - & 149,9 & 148,2 \\
3 & $6,78(s)$ & 114,6 & 113,3 \\
$3 \mathrm{a}$ & - & 131,1 & 129,8 \\
4 & $2,87(d d, 4 \& 13,6)$ & 30,4 & 28,4 \\
& $2,55(d d, 4 \& 10,3)$ & & \\
5 & $2,96(m)$ & 54,1 & 53,1 \\
$6 \mathrm{a}$ & $2,97(m)$ & 63,7 & 62,4 \\
7 & $2,37(d, 12,1)$ & 35,3 & 33,8 \\
& $2,33(d, 10,1)$ & & \\
$7 \mathrm{a}$ & - & 131,9 & 130,2 \\
8 & $6,55(s)$ & 115,6 & 114,2 \\
9 & - & 146,8 & 145,1 \\
10 & - & 147,0 & 145,6 \\
11 & $7,96(s)$ & 112,1 & 110,1 \\
$11 \mathrm{a}$ & - & 124,2 & 123,5 \\
$\mathrm{~N}_{-} \mathrm{CH}_{3}$ & $2,43(s)$ & 44,2 & 43,4 \\
$1-\mathrm{OCH}_{3}$ & $3,84(s)$ & 60,1 & 60,3 \\
$10-\mathrm{OCH}_{3}$ & $3,57(s)$ & 56,4 & 56,1 \\
\hline
\end{tabular}

*Senyawa 2 diukur dalam aseton- $d_{6}$, senyawa 2* diambil dari Guinaudeau dkk. (1975)

Pembuktian lebih lanjut penetapan struktur senyawa 2 ditentukan dengan membandingkan data ${ }^{13} \mathrm{C}$ NMR antara senyawa 2 dan boldin (2*) yang dilaporkan oleh Guinaudeau dkk. (1975) dimana pergeseran kimia dari masing-masing karbon memperlihatkan nilai yang mirip (Tabel 2).

Penemuan dua senyawa turunan alkaloid ini, yaitu $N$-metillaurotetanin (1) dan boldin (2) pada $C$. tawaensis telah memberikan kontribusi penting terhadap fitokimia genus Cryptocarya. Penemuan ini memberikan informasi bahwa spesies C. Tawaensis merupakan spesies dari Genus Cryptocarya yang menghasilkan senyawa alkaloid dan secara kemotaksonomi dapat menjelaskan hubungan kekerabatan tumbuhan penghasil metabolit sekunder golongan alkaloid yaitu antara genus Cryptocarya dengan genus Litsea, Neolitsea, Aniba, Nectandra dan Ocotea, dalam famili Lauraceae.
Sifat sitotoksik dari senyawa $\mathrm{N}$ metillaurotetanin (1) dan boldin (2) ditunjukkan dari nilai nilai $\mathrm{IC}_{50}$ berturut-turut $18.28 \mu \mathrm{g} / \mathrm{mL}$ dan $21.5 \mu \mathrm{g} / \mathrm{mL}$ Dari data tersebut memperlihatkan bahwa kedua senyawa tersebut tidak bersifat sitotoksik terhadap sel murine leukemia ( $\mathrm{P}-388$ )

\section{Kesimpulan}

Dua senyawa alkaloid aporfin, $N$ metillaurotetanin (1) dan boldin (2) telah berhasil diisolasi dari kulit batang Cryptocarya tawaensis Merr. N-metillaurotetanin (1) sebelumnya pernah ditemukan dalam Cryptocarya longifolia sedangkan senyawa boldin (2) baru pertama kali ditemukan dalam genus tumbuhan Cryptocarya. Dengan ditemukannya kedua senyawa dalam $C$. tawaensis Merr., dapat disimpulkan bahwa spesies ini dapat dikelompokkan ke dalam tumbuhan Cryptocarya penghasil alkaloid. 


\section{Daftar Pustaka}

[1] Bick, R.C., dan Sinchai, W. (1978): Alkaloids of the Lauraceae, Heterocycles, 9(7), 903.

[2] Juliawaty, L.D., Aimi,N., Ghisalberti, E.L., Kitajima, M., Makmur, L., Syah, Y.M., Siallagan, J., Tahayaka, H., Achmad, S.A., dan Hakim, E.H. (2006) : Chemistry of Indonesian Cryptocarya plants (Lauraceae), Chemistry of Natural products: Recent Trends \& Developments, 339-423.

[3] Gottlieb, O. R. (1972) : Chemosystematics of the Lauraceae, Phytochemistry, 11, 1537-1570

[4] Guinaudeau,, H., Leboeuf, M., dan Cave', A. (1975): Aporphine alkaloids. Lloydia, 38, 275-338. 